be refilled. It can be cleaned by washing with soap and water, and chemically sterilized by keeping it in 1:1000 mercuric bichloride or in chlorine solution (Solvellae Chloramine B.P.C: in $4 \mathrm{oz}$. water) for $15-20$ minutes, followed by rinsing. Alcoholic solutions, phenolic antiseptics or heat sterilization are not suitable, as they are detrimental to the plastic material of which the applicator is made.

The contact applicator can be used for any solutions such as sulphonamides, mydriatics, miotics, urea, etc. Struble and Bellow's (1944 and 1946) have shown that a high concentration of penicillin in the anterior segment of the eye can be built up by the use of a corneal bath, and they have advocated this procedure for the treatment of corneal ulcers, particularly if the deeper layers are involved. In chemical burns the applicator can be used for continuous irrigation with the antidote, such as ammonium tartarate solution in lime-burns. For irrigation a suitably placed flask or undine can be connected with rubber tubing.

The contact applicator is manufactured by Messis. G. Nissel and Co. Ltd., Siddons Lane, London, N. W.1.

\title{
REFERENCES
}

Ridley, F. T. (1931)-Proc. Roy. Soc. Med., 25, 480.

KLEIN, M. (1942)-Trans. Ophth. Soc. U.K., 62, 43.

Struble, G. C. \& Bellows, J. G. (1944)-J.A.M.A., 125, 485.

Struble, G. C. \& Bellows, J. G. (1946)-Arch. Ophth., 35, 173.

\section{FACULTY TOUR OF ITALIAN CLINICS}

UNDER arrangements made by the Faculty of Ophthalmologists, twenty members, led by Dr. Robert Buxton, were able to make a tour of 'centres of ophthalmology in Italy, the clinics visited being those at Pavia, Genoa, Florence, Rome, Naples and Bologna. At each of these places the hospitality of the professors, and the opportunities for seeing the beauties of their cities, contributed greatly to the enjoyment of what was, in any case, an interesting and instructive tour.

At Pavia the party was welcomed by Professor Bietti and taken to a reception given by the Rector of the University of Pavia. In one of the courtyards of the University is a statue of Scarpa, the first Professor of Ophthalmology of Pavia.

At the Ophthalmic Clinic next morning Professor Bietti showed a number of cases on which keratoplasty had been performed, and demonstrated his technique. He also gave a lecture on Chemotherapy in Tuberculosis. $\mathrm{He}$ advised early administration of streptomycin $(0.5 \mathrm{gm}$. b.d. subcutaneously) which may be given with 
Promin in a $50 \mathrm{gm}$. course. He also referred to the use of Paraamino-salicylic acid (P.A.S.), which is well tolerated and rapidly absorbed. The bacteriostatic action of the drug may be obtained by a dosage of $10-15 \mathrm{gm}$. daily (divided into four doses) given in three week courses; it may be combined with streptomycin therapy. $\mathrm{He}$ also gave a second lecture on new trends in diathermy of the ciliary body.

Dr. Malone, First Assistant to Professor Maggiore at Genoa, demonstrated a patient wearing contact lenses with variable curve who was able to see $6 / 6,6 / 9$ and also read newsprint without additional correction. A visit was arranged to the San Giorgio Optical Company.

The Ophthalmic Clinic at Florence is a spacious modern building with an extensive out-patient department. Separate accommodation is provided for trachoma cases, but the number is stated not to be large at the present time. Professor Alajmo demonstrated his technique in several operations. He uses no speculum, lid sutures nor superior rectus sutures. Soft lens matter is removed by irrigation with a long-necked undine placed directly in the anterior chamber, the corneal flap being lifted with forceps.

Professor Cavara at Rome, gave a most interesting and instructive lecture on virus diseases of the uveal tract, including a useful classification of the various types. He recommends protein therapy, urotropine and plasma transfusions (especially the latter for sympathetic ophthalmia), using American dried plasma or, preferably, fresh plasma. The first (trial) dose of the latter is 100 c.c. intravenously, after two days $150-200$ c.c. Total, five to six doses given at three day intervals. Milk injections have not produced good results.

His second lecture was on streptomycin and P.A.S. He gives 1.0 $\mathrm{gm}$. of the former daily in two to four injections, for twenty to forty days, exceptionally up to sixty days, and observed the results to be satisfactory in twenty-nine cases of uveal tuberculosis, and brilliant in two cases of Parinaud's conjunctivitis. In two cases of choroiditis, one of juxta-papillary choroiditis and two of nodular irido-cyclitis he considered that healing was accelerated. In ocular tuberculosis produced by inoculating rabbits with T.B., he found that whereas streptomycin controlled the infection, P.A.S. had much less effect in checking the disease. The former encouraged fibrotic reaction, the latter cellular. In untreated controls caseation occurred. Professor Cavara then showed a number of cases including a retinal detachment due to cysticercus. This was one of eight cases received from one village, the source of infection being pork. $\mathrm{He}$ prefers to extract the cyst through a linear incision through sclera and uvea, which he makes as small as possible to avoid perforating 
the retina at the edges of the cyst. Among other cases demonstrated were opacity of corneal stroma in two children, brother and sister, due apparently to congenital absence of Descemet's membrane, congenital atrophy of iris with chronic glaucoma, mobile cysts in anterior chamber following keratoplasty, lacrimation when chewing but not when crying, associated in this instance with Stilling-Turck syndrome, a case of Marcus Gunn's syndrome successfully treated by dividing the levator tendon of the lid and correcting the subsequent ptosis by a modification of Hess's operation, and finally a case of keratoconus, grafted, with the graft remaining flat but the surrounding cornea continuing to stretch.

The assistant professor, Dr. Missiroli, demonstrated his technique in operations for cataract, glaucoma and detached retina.

While in Rome a visit was paid to the Provincial Ophthalmic Hospital, a non-teaching establishment under the care of Dominican nuns. Professor Leonardi demonstrated various different techniques in cataract extraction, including intra and extra-capsular methods, the former with forceps, erisiphake, and diathermy coagulation in turn.

Members of the party will long remember the hospitality afforded to them by Professor Cavara during their stay in Rome, for during unoccupied moments they were not only enabled to see at least some of the famous buildings but also were present at the opera and enjoyed a sumptuous banquet given by Professor Cavara and his wife. Finally, they were honoured by an audience with His Holiness Pope Pius XII.

Much interest was aroused by the demonstrations of operative dexterity given by Professor Lo Cascio of Naples. Using two operating tables and four trained assistants he performed, without any appearance of haste, seven extra-capsular operations in fifty minutes, followed by three cyclodialyses and a diathermy operation for detachment of the retina. The technique he employs in the latter is careful localisation of the hole or holes by indirect ophthalmoscopy, and he inspects the fundus by this method again immediately after applying surface diathermy. The fluid is let out by one or more punctures at the site of the greatest ballooning. He has operated on many hundreds of detachments, and claims 75-80 per cent. successes.

Lastly, at Bologna Professor Di Marzio welcomed the party and gave an address on a subject in which he is particularly interested, that of cranial and cranio-orbital lesions which affect the visual neural paths, with especial reference to the chiasmatic syndrome. He showed records of cases with bitemporal, binasal and homony-. mous field defects. Slides were exhibited, showing the correlation between field changes and radiological appearances. Most of the 
cases were treated with deep $\mathrm{X}$-rays, and the results appear to have been good. (X-ray therapy is much used by Di Marzio in cases of inflammatory diseases of the eye. He gives $100 \mathrm{r}$. once or twice a week for such conditions as central serous retinitis, ulcerative keratitis and iridocyclitis).

His assistant, Dr. G. Cristini, gave a lecture on the radiographic investigation of obscure lesions of the optic nerves, and described his technique for inserting lipiodol into the paranasal sinuses, and also for injecting thorotrast into the carotid artery for cerebral arteriography.

Apart from the interest and instruction which this tour afforded from the professional point of view, and from the opportunity of seeing some of the most famous of the world's treasures in pictures, sculpture and architecture, no member of the party could fail to be impressed with the evident trouble taken by the various hosts on behalf of their visitors, a debt which it is hoped in some measure to repay here next year. Finally, a word of sincere appreciation for the unselfish and unflagging efforts by the party leader Dr. Robert Buxton, who planned the tour and spared no pains to make it the success it proved to be.

Ophthalmological

Society of Egypt

\section{NOTES}

IN connection with the recent announcement of an award by the Ophthalmological Society of Egypt it is ruled that this prize is designated only for members of the Society, either in Egypt or abroad, who have been in practice less than 20 years.

Appointment

Ophthalmological Society of Australia
DR. E. V. SRINIVASAN has been appointed Hon. Ophthalmic Surgeon to His Excellency the Governor General of India.

Mr. J. H. Doggart and Mr. T. K. Lyle have been elected Honorary Members of the Ophthalmological Society of Australia. 